Please do not remove this page

RMIT

UNIVERSITY

\title{
Thermal comfort characteristics of knitted fabrics for Abaya
}

Tashkandi, Salwa; Wang, Lijing; Kanesalingam, Sinnappoo; Jadhav, Amit

https://researchrepository.rmit.edu.au/esploro/outputs/9921859352001341/filesAndLinks?institution=61RMIT_INST\&index=null

Tashkandi, S., Wang, L., Kanesalingam, S., \& Jadhav, A. (2013). Thermal comfort characteristics of knitted fabrics for Abaya. Advanced Materials Research, 627, 164-169.

https://doi.org/10.4028/www.scientific.net/AMR.627.164

Published Version: https://doi.org/10.4028/www.scientific.net/AMR.627.164

Repository homepage: https://researchrepository.rmit.edu.au

(C) (2013) Trans Tech Publications, Switzerland.

Downloaded On 2023/04/26 21:29:16 +1000

Please do not remove this page 
Thank you for downloading this document from the RMIT Research Repository.

The RMIT Research Repository is an open access database showcasing the research outputs of RMIT University researchers.

RMIT Research Repository: http://researchbank.rmit.edu.au/

\section{Citation:}

Tashkandi, S, Wang, L, Kanesalingam, S and Jadhav, A 2013, 'Thermal comfort characteristics of knitted fabrics for abaya', Advanced Materials Research, vol. 627, pp. 164-169.

See this record in the RMIT Research Repository at:

http://researchbank.rmit.edu.au/view/rmit:19914

Version: Accepted Manuscript

Copyright Statement: (c) (2013) Trans Tech Publications, Switzerland.

Link to Published Version:

http://dx.doi.org/10.4028/www.scientific.net/AMR.627.164 


\title{
Thermal Comfort Characteristics of Knitted Fabrics for Abaya
}

\author{
Salwa Tashkandi ${ }^{1,2, a}$, Lijing Wang ${ }^{1, b}$, S.Kanesalingam ${ }^{1, c,}$ Amit Jadhav ${ }^{1, d}$ \\ ${ }^{1}$ School of Fashion and Textiles, RMIT University, Melbourne, Australia \\ ${ }^{2}$ Department of Fashion and Textile, King Abdul Aziz University, Jeddah, Kingdom of Saudi Arabia

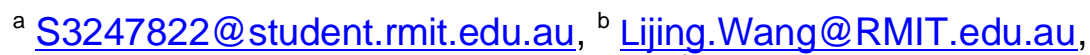 \\ c sinnappoo.kanesalingam@rmit.edu.au, ${ }^{d}$ amit.jadhav@rmit.edu.au
}

Keywords: Abaya, thermal comfort, thermal resistance, air permeability, knitted fabric.

\begin{abstract}
Fabric material plays an important role in the thermal comfort of Abaya because it is the outer garment of Muslim women. Abaya is black in colour and covers the whole body except the hands, feet and face. It is mandatory to wear Abaya in the Saudi Arabia and certain parts of Middle East countries irrespective of the outside environmental temperature which could be up to $45^{\circ} \mathrm{C}$. Therefore, the thermal transmission characteristics of the abaya are extremely important as human body responds to the external thermal environment through clothing. In a hot environment, it is extremely uncomfortable to wear several layers of clothing under the Abaya. Hence it is essential to enhance the thermal comfort of fabrics used for Abaya. This study investigated five selected knitted fabrics that could be used as Abaya fabrics for thermal resistance, air permeability, thermal comfort and vapour resistance. The results indicated that the fabrics with different knit structures, fibre composition and fabric weight have greater influence on thermal comfort performance.
\end{abstract}

\section{Introduction}

Women wearing Abaya in the Arabian Gulf do so to cover whole body (Fig. 1). The scarf and veil are worn in order to cover the head and face respectively. Abaya is worn from the shoulder or from the top of head over the normal day-to-day clothing when she leaves home. It reflects the individual's strong Arabian cultural heritage and religious belief. Statistics showed that $49.7 \%$ of women in Saudi Arabia aged over 10 years, corresponding to an estimated 9.5 million females [1] wear Abaya. Saudi Arabian religious police enforce the wearing of Abaya for all women, even for the female foreigners. Considering the extreme climate in Saudi Arabia where in summer, day time temperature sometimes exceeds $45^{\circ} \mathrm{C}$, wearing Abaya is very uncomfortable. Considering Abaya is the mandatory outermost garment for women to be worn in Saudi Arabia, Abaya fabric material is of significant interest for research to improve the garment comfort performance.
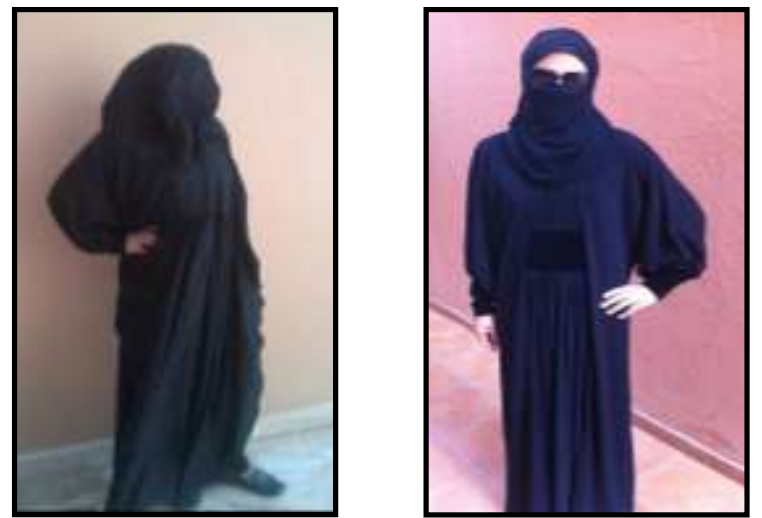

Fig. 1. Abaya knitted fabrics.

During last few years the thermal comfort performance of textiles has improved, and started to become more significant especially for functional clothing such as protective, athletic and smart 
garments as a result of consumer's demands [2]. When the body is sweating, the garment worn next to skin should allow the perspiration to pass through fabric layers to the outside of clothing ensemble in order to reduce the humidity on the surface of the skin. The sensation of discomfort in the textile fabric is mainly caused if the fabric is blocking the passage of water vapour to transfer to the outside atmosphere [3].

Thermal comfort properties of textile fabrics are influenced by a range of fibre, yarn and fabric properties [2-5]. Many researchers worked on to improve comfort performance in clothing [6-10]. However, as of date limited research has been undertaken to assess the thermal comfort properties of Abaya. Therefore, the present study aims to investigate the thermal comfort properties of this type of garment. In this paper, five types of knitted fabrics for Abaya were analyzed to determine whether they can be used to produce comfortable Abaya garments for hot environments.

Majority of women are interested in following up the fashion trend in cloths. Every woman in Saudi Arabia desires to look beautiful in Abaya, regardless of the extent of their knowledge of fabrics used. Traditionally, only woven fabrics were used for Abaya. Recently Abaya made from knitted fabrics (Fig. 1) become a fashion choice for evening wear. It is believed that the porosity, stretch and recovery and low weight of knitted fabrics may assist in the movement of air and hence improve Abaya comfort performance. Because of this, it is important to examine knitted fabrics to select suitable knitted fabrics for Abaya.

\section{Experimental}

All samples were tested according to Australian, ISO or BS standards, if applicable, under the standard testing conditions, i.e. temperature of $20 \pm 2^{\circ} \mathrm{C}$ and $65 \pm 2 \%$ relative humidity (R.H.), or specified conditions. All samples were conditioned for at least 24 hours before testing.

Fabric Characteristics. Five knitted fabrics that may be useful for Abaya were selected and analyzed. The knitted fabrics were Nylon (N), Wool/Nylon (WN), Wool (W), Polyester/Cotton (PC) and Polyester/Elastane (PE) (see Table 1 for fabric information). Their physical parameters such as fabric materials type, construction, mass per unit area (AS 2001.2.13-1987), fabric thickness (AS 2001.2.15-1989), wales and courses per unit length (stitch density), and optical porosity \% were determined. Motic stereo microscope and Motic image software was used to determine fabric optical porosity, which was calculated with Eq. 1. Test parameters related to comfort characteristics including drape coefficient, stretch and recovery, air permeability, thermal resistance and vapour resistance of the knitted fabrics were tested.

$$
\text { Optical porosity } \%=\frac{\text { Black pixels }}{\text { Black pixels }+ \text { White pixels }} \times 100
$$

Evaluation of Fabric Properties. Fabric drape was measured according to the BS 5058:1973 using a drapemeter from Cusick Drape Tester to measure the drape coefficient values. The stretch and recovery properties of the knitted samples were tested by an Instron according to the British standard 4952:1992. Five specimens each from wales and courses direction were tested. The dimensions of specimen between clamps are $75 \times 75 \mathrm{~mm}$, i.e. the gauge length $\left(\mathrm{L}_{1}\right)$ was $75 \mathrm{~mm}$. The fabric was stretched to $30 \mathrm{~N}$ force at a rate of $100 \mathrm{~mm} / \mathrm{min}$ and the load was maintained for $10 \mathrm{~s}$, after which the extension (cross-head movement) was recorded as $\left(\mathrm{L}_{3}\right)$. Then the sample was removed from the clamps and allowed to relax on a flat, smooth surface and its length was re-measured after 1 min as $\left(\mathrm{L}_{2}\right)$. The stretch and recovery results can be calculated by Eq. 2 \& Eq. 3, respectively:

$$
\begin{aligned}
& \text { Extension at } 30 \mathrm{~N}, E=\frac{\mathrm{L}_{3}}{\mathrm{~L}_{1}} \times 100 \% \\
& \text { Residual extention after } 1 \mathrm{~min}, R_{1}=\frac{\left(\mathrm{L}_{2}-\mathrm{L}_{1}\right)}{\mathrm{L}_{2}} \times 100 \%
\end{aligned}
$$

Fabric air permeability was measured according to the testing standard EN ISO 9237:1995 by using the air permeability tester M021S. However, the air permeability was measured with $50 \mathrm{~Pa}$ 
pressure difference across the tested fabric, as some fabrics cannot reach the $100 \mathrm{~Pa}$ pressure difference, as suggested by the testing standard. Sweating Guarded Hot Plate (M259B) instrument (conforming to ISO 11092:1993) from SDL ATLAS instrument was used to measure thermal resistance and water vapour resistance.

\section{Results and Discussion}

Physical Properties of Knitted Fabrics. Fabrics were analyzed and their properties are shown in Table 1. Fabric $\mathrm{N}$ is the heaviest, thickest and lowest in stitch density as well as in optical porosity amongst all the fabrics. This is because of coarser yarn and the interlock knit structure. Fabric PE is heavier and higher in stitch density than WN, PC and W. PC and W fabrics have a similar weight and stitch density but different thickness and structure. PC is thicker than $\mathrm{W}$ because it has double jersey knit structure.

Table 1: Physical properties of experimental knitted fabrics.

\begin{tabular}{cccccc}
\hline & Nylon (N) & $\begin{array}{c}\text { Wool/Nylon } \\
(\mathbf{W N})\end{array}$ & Wool (W) & $\begin{array}{c}\text { Polyester/ } \\
\text { Cotton (PC) }\end{array}$ & $\begin{array}{c}\text { Polyester/ } \\
\text { Elastane (PE) }\end{array}$ \\
\hline Knit structure & Interlock & Single jersey & Single jersey & Double jersey & Single jersey \\
\hline Fiber composition & $\begin{array}{c}100 \% \\
\text { Nylon }\end{array}$ & $\begin{array}{c}50 / 50 \\
\text { Nylon/Wool }\end{array}$ & $\begin{array}{c}100 \% \\
\text { Wool }\end{array}$ & $\begin{array}{c}65 / 35 \\
\text { Polyester/ } \\
\text { Cotton }\end{array}$ & $\begin{array}{c}\text { Polyester/ } \\
\text { Elastane }\end{array}$ \\
\hline Yarn structure & Filament & $\begin{array}{c}\text { Wool: spun, } \\
\text { Nylon: } \\
\text { filament }\end{array}$ & Spun yarn & Spun yarn & Filament \\
\hline Fabric weight [g/m $\mathbf{m}^{\mathbf{2}}$ ] & 349 & 127 & 174 & 176 & 184 \\
\hline Thickness [mm] & 1.15 & 0.64 & 0.54 & 0.8 & 0.5 \\
\hline Courses/cm & 18 & 16 & 20 & 20 & 22 \\
\hline Wales/cm & 12 & 15 & 17 & 15 & 20 \\
\hline Optical porosity[\%] & 1.45 & 8.51 & 5.64 & 8.66 & 6.45 \\
\hline
\end{tabular}

Fabric Drape. The average values of fabric drape coefficient (DC) in Fig. 2 show that the DC range is from $20 \%$ to $50 \%$. This means the drape of the fabrics is between limp and medium fabric category [11]. Fabrics W, WN and PE exhibit better drapeability than PC and N, because they are thin and more drapeable. This means fabrics $\mathrm{W}, \mathrm{WN}$ and PE could be more suitable for Abaya. In contrast, fabric $\mathrm{N}$ shows higher drape coefficient which means the fabric is stiffer than other fabrics and it could be uncomfortable to wear.

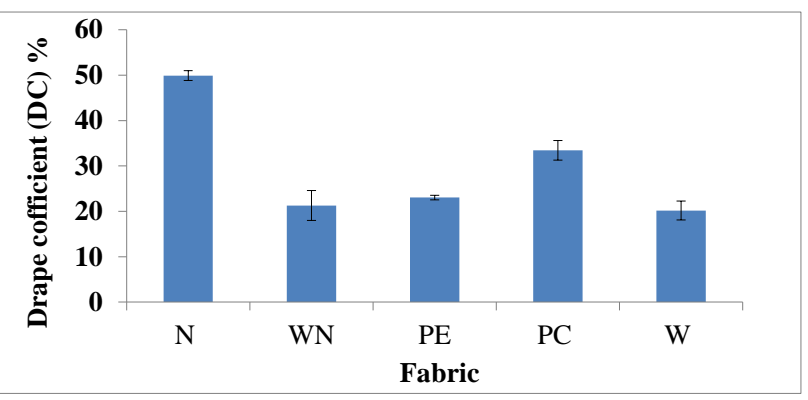

Fig. 2. Comparison of drape coefficient of Abaya knitted fabrics.

Stretch and Recovery. It is expected that Abaya should have excellent recovery properties in wales direction to maintain its original shape. A higher percentage of recovery after stretching indicates better stretch and recovery property of knitted fabrics [12]. The stretch and recovery properties in Fig. 3 and Fig. 4 indicate that PE has the highest stretchability in the wales direction and lower residual 
extension in course direction compared to other fabrics. This is most likely due to the presence of Elastane filament. Fabric W shows lower residual extension compared to the rest of the fabrics possibly due to its single jersey structure.

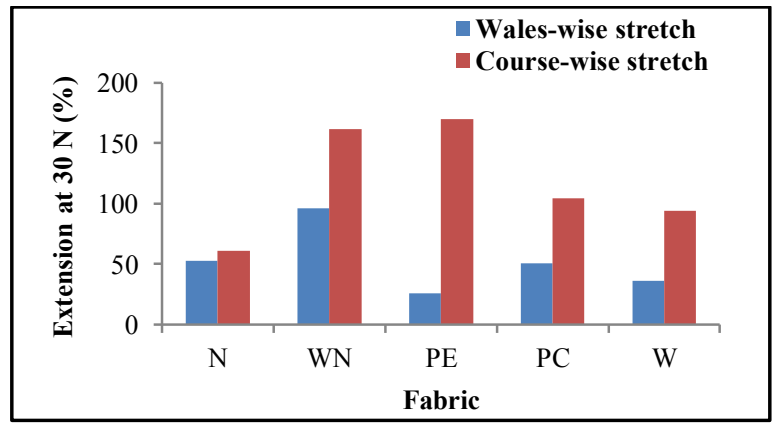

Fig. 3. Stretchability of Abaya knitted fabric

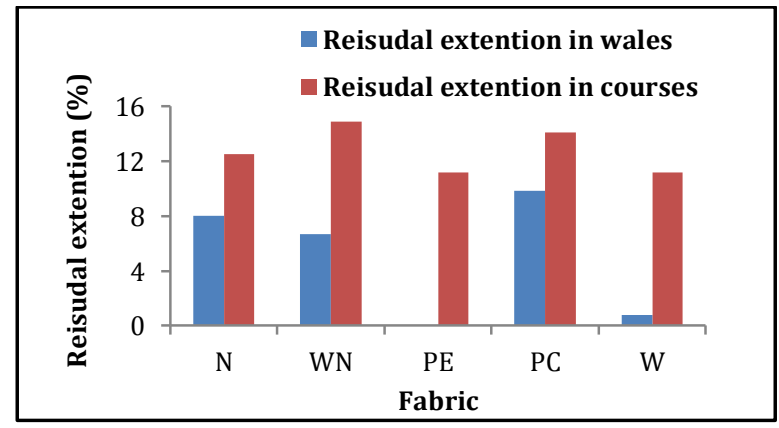

Fig. 4. Recovery of Abaya knitted fabric

Air Permeability. Higher air permeability facilitates the removal of moisture in hot weather and reduces perspiration discomfort. Fig. 5 shows that all tested fabrics are highly air permeable except Fabric N. Fabrics WN and PC have a higher air permeability value than other fabrics. This is because these two fabrics have higher optical porosity (Table 1) and lower courses/cm, which facilitates more air to pass through. However, PE and $\mathrm{W}$ also show high air permeability. This may be due to the single jersey structure and optical porosity as well. $\mathrm{N}$ showed lowest air permeability than all other samples due to its interlock knit structure which makes the fabric less porous hence it restricts the flow of air through the loops and also $\mathrm{N}$ fabric is heavier and more thicker compared to other fabrics.

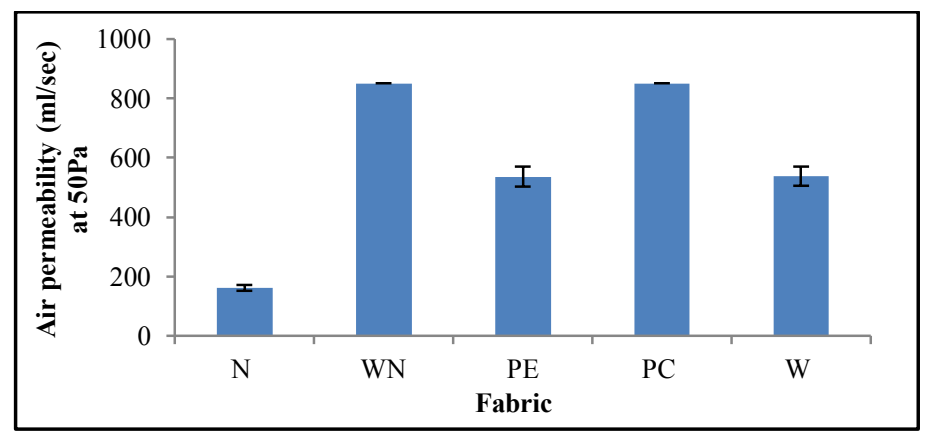

Fig. 5. Comparison of air permeability

Thermal Resistance. For a hot environment, low thermal resistance is necessary to allow the heat from the body flowing outside to the environment. In Fig. 6, the thermal resistance of sample $\mathrm{N}$ showed the lowest value among all the sample fabrics because fabric $\mathrm{N}$ was made of $100 \%$ nylon filaments and nylon filament has higher thermal conductivity $(0.25 \mathrm{~W} / \mathrm{mK})$ compared to other fibres used [13]. Therefore it allows more heat to pass through the fabric. PE sample also shows a lower thermal resistance because polyester filament has better thermal conductivity $(0.14 \mathrm{~W} / \mathrm{mK})[13]$ than wool $(0.039 \mathrm{~W} / \mathrm{mK})$ and cotton $(0.029 \mathrm{~W} / \mathrm{mK})$ fibres [14]. WN, W and PC samples showed higher thermal resistance.

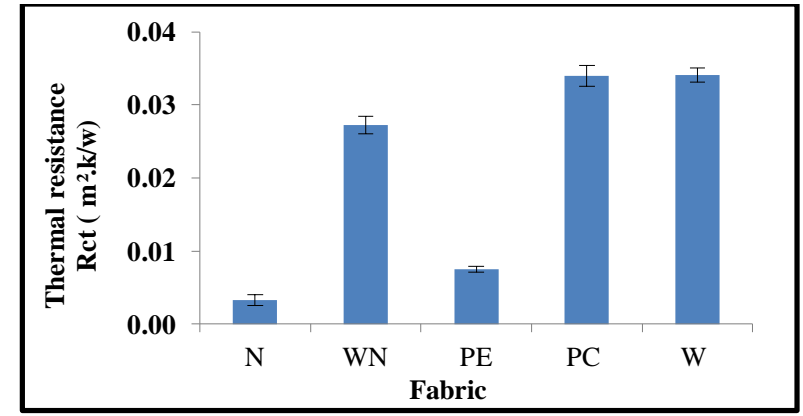

Fig. 6. Comparison of thermal resistance $\mathrm{R}_{\mathrm{ct}}$

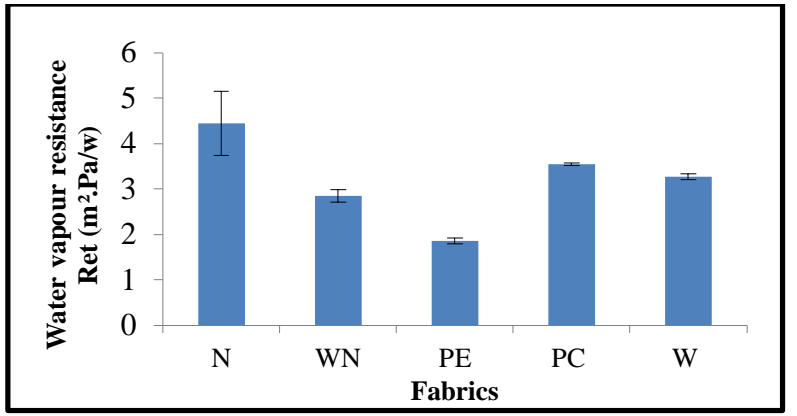

Fig. 7. Comparison of water vapour resistance $\mathrm{R}_{\mathrm{et}}$ 
Water Vapour Resistance. It can be observed from Fig. 7 that fabric PE has a lower value of water vapour resistance among all the fabrics. This is due to lower fabric thickness. A lower water vapour resistance value is desirable for better moisture transport to pass through the fabric and into the environment, resulting in drier skin thereby improving thermal comfort [7]. Higher value of water vapour resistance of fabric results in the lower vapour transmission from body to outside environment, therefore body feels discomfort [7]. However, water vapour resistance of $\mathrm{N}$ appears higher than rest of the samples. This is due to higher thickness and compactness of interlock structure.

\section{Conclusion}

This study was to understand knitted fabrics used for Abaya and investigate their thermal comfort properties. Experimental results showed that knit structure, fibre composition and other fabric properties affect the thermal comfort performance. The polyester/elastane (96/4) single jersey knit fabric showed better air permeability, stretch $\&$ recovery properties, lower thermal \& water vapour resistance compared to nylon filament fabric, polyester/cotton (65/35) single jersey, wool single jersey fabric, and 50/50 wool/nylon fabric. It is evident that the knitted polyester/elastane fabric construction appears to be more suitable for Abaya fabric.

\section{Acknowledgment}

We express our sincere gratitude and thanks to the Government of Kingdom of Saudi Arabia for providing PhD Scholarships through the King Abdul Aziz University to the first author.

\section{References}

[1]. CDSI, Highlights population \& housing census 1430 h (2010) Retrieved 2-5-2012, 2012, from http://www.cdsi.gov.sa/component/content/article/143. (2012)

[2]. S. Kaplan, and A. Okur, A new dynamic sweating hotplate system for steady-state and dynamic thermal comfort measurements, Measurement Science and Technology, 21, (2010), p. 085701.

[3]. M. Srdjak, Water vapour resistance of knitted fabrics under different environmental conditions, Fibres \& Textiles in Eastern Europe, 17(2), (2009), p. 73.

[4]. G. Bedek, F. Sala $\sqrt{ }{ }^{\circ}$ n, Z. Martinkovska, E. Devaux, and D. Dupont, Evaluation of thermal and moisture management properties on knitted fabrics and comparison with a physiological model in warm conditions, Applied ergonomics, 42(6), (2011), p. 792.

[5]. C. Prakash, G. Ramakrishnan, and C.V. Koushik, A study of the thermal properties of bamboo knitted fabrics, Journal of Thermal Analysis and Calorimetry, (2012), p. 1.

[6]. F. Al-Ajmi, D.L. Loveday, K. Bedwell, and G. Havenith, Thermal insulation and clothing area factors of typical arabian gulf clothing ensembles for males and females: Measurements using thermal manikins, Applied ergonomics, 39(3), (2008), p. 407.

[7]. J. Fan, and H.W.K. Tsang, Effect of clothing thermal properties on the thermal comfort sensation during active sports, Text. Res. J., 78(2), (2008), p. 111.

[8]. N. Nawaz, O. Troynikov, and C. Watson, Thermal comfort properties of knitted fabrics suitable for skin layer of protective clothing worn in extreme hot conditions, Advanced Materials Research, 331, (2011), p. 184.

[9]. G. Song, "Improving comfort in clothing", (1st ed.). Philadelphia: Woodhead Publishing Ltd, 2011.

[10]. O. Troynikov, and W. Wardiningsih, "Comfort properties of fabrics for winter sportswear", (1st ed.). Saarbrücken, Germany: VDM Verlag Dr Mueller, 2010.

[11]. J. HU, "Fabric testing". Cambridge, The Textile Institute, CRC Press,: Woodhead Publishing Limited, 2008.

[12]. J. Yip, and S.P. Ng, Study of three-dimensional spacer fabrics:: Physical and mechanical properties, Journal of materials processing technology, 206(1), (2008), p. 359.

[13]. N. Mao, and S. Russell, The thermal insulation properties of spacer fabrics with a mechanically integrated wool fiber surface, Textile Research Journal, 77(12), (2007), p. 914.

[14]. A. Majumdar, S. Mukhopadhyay, and R. Yadav, Thermal properties of knitted fabrics made from cotton and regenerated bamboo cellulosic fibres, International Journal of Thermal Sciences, 49(10), (2010), p. 2042. 